\title{
Infestation of Rice Root-Knot Nematode in Rice Nurseries in Chitwan
}

\author{
N. K. Dangal ${ }^{1}$, S. M. Shrestha ${ }^{2}$, D. Sharma-Poudyal ${ }^{3}$ and C. Adhikari ${ }^{4}$ \\ ${ }^{1}$ Dabur Nepal Pvt. Ltd., Kathmandu, Nepal \\ ${ }_{2}^{2}$ Institute of Agriculture and Animal Science, Rampur, Chitwan, Nepal \\ ${ }^{3}$ Department of Plant Pathology, Washington State University, Pullman, WA, USA \\ ${ }^{4}$ CIMMYT-SARO, Singha Durbar Plaza, Kathmandu, Nepal \\ e-mail:nabindgl@yahoo.com
}

\begin{abstract}
A survey was conducted during June-July 2006 in Chitwan to find out the natural infestation of rice root-knot nematode (Meloidogyne graminicola Golden \& Brichfield) in rice nurseries. Thirty nurseries were surveyed and 100 seedlings from each nursery were evaluated. Field survey revealed that M. graminicola was widely distributed in most rice growing areas of Chitwan District. Rice root-knot disease was more prevalent in dry bed condition than wet bed. Most of the farmers grew seedlings in upland (dry) soil and there was more rice root-knot disease and second stage juvenile (J2) population in both nursery soil and seedling root. The galled (diseased) seedlings had significantly shorter roots and shoots. Most of the farmers did not know about the nematode problem and did not follow any management practices to control it in nurseries and/or in the main field. This indicated high risk of multiplication of the nematodes and huge loss in rice production. Thus, it is essential to manage M. graminicola in rice nurseries in order to produce healthy seedlings.
\end{abstract}

Key words: dry bed, lowland, Meloidogyne graminicola, upland, wet bed

\section{Introduction}

Rice (Oryza sativa L.) is the first leading cereal of Nepal representing about $25 \%$ of total cultivated area and about $28 \%$ of total cereal production (NARC 2001). It is the most preferred staple food in Nepal and mainstay for the food security of rural population. The crop is grown in all agro-ecological zones like Terai (100-300 masl), valleys, foot hills (300-1000 masl) and high hills up to 2600 masl (Dhital et al. 1995).

The major constraints in rice production are plant diseases and insects; nutrient deficiency; mid and late season water stress; water management, and weeds for direct seeded rice (Kataki et al. 2001). Kataki (2001) reported that pests and diseases were paramount problem in rice. Among the foliar diseases, blast, bacterial blight, and sheath blight are considered as the important ones (Dahal et al. 1995) whereas the soil borne diseases specially diseases caused by plant parasitic nematodes (PPNs) are major bottlenecks to crop productivity in the high input intensive cropping systems such as the rice and wheat based cropping systems (Sharma \& Rahaman 1998).

More than 200 species of PPNs have been reported to be associated with rice (Prot 1994). Rice root-knot nematodes (Meloidogyne spp.), rice root nematode (Hirschmanniella oryzae), white tip nematode (Aphlenchoides besseyi) and stem nematode (Ditylenchus angustus) are the important PPNs associated with rice based cropping systems (Sharma \& Rahaman 1998). Among them, the rice root-knot nematodes (Meloidogyne sp.) are considered as the major problem in rainfed, upland and lowland rice fields whereas the rice root nematodes (Hirchmanniella sp.) are problematic on low land rice growing areas of South and Southeast Asia (Prot 1994). Among Meloidogyne sp., the rice root-knot nematode (M. graminicola Golden and Birchfield) attacking rice and wheat, is considered the most serious nematode in upland rice cultivation (Panwar \& Rao 1998) and causes economic 
losses in upland, lowland, and deep water rice and also in rice nurseries (Bridge et al. 1990). This pest has been reported from the main rice growing areas of Nepal (Pokhrel 2001, Pokharel and Sharma-Poudyal 2001, Sharma et al. 2001, Sharma-Poudyal et al. 2002, Dangal et al. 2008). Pokharel and Sharma-Poudyal (2001) observed high population levels of M. graminicola in farmers' rice fields in Chitwan, Rupendehi, Bara, Parsa, and Rautahat districts of Nepal. Furthermore, Sharma et al. (2002) also reported rice root-knot nematode in both rice and wheat fields under rice-wheat system from Bara, Parsa and Rauthat districts. Recently Pokharel (2007) reported that $M$. graminicola was the only root-knot nematode identified from 33 rice-wheat fields representing diverse rice growing areas from the hills to Terai in Nepal.

Soriano et al. (2000) reported that rice cultivar tolerance to M. graminicola varied with water regime. Similarly, adaptability of $M$. graminicola in different physiographic regions further aggravates the disease situation in Nepal (Pokharel 2007). However, detail information on the biology of root-knot nematode in rice field as well as its sustainable management are limited in Nepal (Pokharel 2007). Since, most of the commonly grown Nepalese rice cultivars are susceptible to $M$. graminicola (Sharma-Poudyal et al. 2004, Pokharel 2007), there may be rice yield loss in every $M$. graminicola infested nursery and field. Hence there is an urgent need of practical nematode management options for the farmers of Nepal. Thus, this study was conducted to study the level of infestation of $M$. graminicola in rice nurseries in Chitwan district.

\section{Materials and Methods}

A survey was conducted during June-July 2006 in eastern (Khairahani and Chainpur V.D.C.) and western (Patihani, Shivanagar, Gunjanagar, Sukranagar, Parsadhap, Meghauli, Divyanagar, Bhimnagar and Saradanagar V.D.C.) parts of Chitwan district to find out the natural infestation of $M$. graminicola in rice nurseries. Information on cropping history, type of soil, seeding methods, rice varieties, date of seeding, type of seed bed, seed and soil treatment etc were gathered from 30 fields. Plants were sampled from 10 spots in ' $M$ ' fashion from each nursery. From each spot, 10 plants were gently uprooted and washed with running tap water to remove soil and other materials. Root length, shoot length, fresh root and shoot weight were recorded. $M$. graminicola second juveniles (J2) present in root and soil were also assessed. The cleaned roots were indexed for root lesion indexing with the help of the following 04 scale according to Sharma-Poudyal et al. (2002):

$0=$ Healthy roots, without lesion,

$1=$ Lesion up to $25 \%$ of roots or $25 \%$ roots rotten,

$2=$ Lesion up to $50 \%$ of roots or $50 \%$ roots rotten,

$3=$ Lesion up to $75 \%$ of roots or $75 \%$ roots rotten and

$4=$ Lesion more than $75 \%$ of roots or more than $75 \%$ roots rotten.

The roots were also indexed for root-knot indexing by the use of 0 (no root swellings or galls) to 10 (all roots galled) scale according to Bridge et al. (2005). Root-knot severity index and root lesion severity index were calculated as follows:

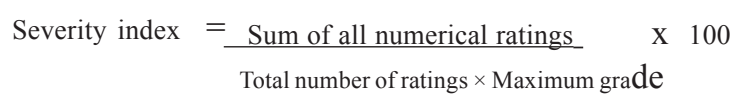

The rice roots were thoroughly washed and chopped into small pieces of about $10 \mathrm{~mm}$ length for extracting M. graminicola second juveniles (J2). About $2 \mathrm{~g}$ of chopped roots were placed in an electric blender with $100 \mathrm{ml}$ of water, blended for 2 minutes and placed in a modified Baermann tray for extraction (Schindler 1961). Similarly, for extracting J2 nematodes from the rhizosphere soil, it was homogenized and $100 \mathrm{~g}$ working sample was taken and processed by modified Baermann tray method (Schindler 1961). After 48 hours of processing, nematode suspension was collected in plastic tubes $(50 \mathrm{ml})$. After allowing standing for an hour, the final volume of suspension was reduced to $20 \mathrm{ml}$ with the help of a glass pipette. Two milliliter (10\%) aliquot was sampled from the $20 \mathrm{ml}$ suspension in counting disc, allowed to settle for five minutes. J2 were counted under a binocular microscope (Bridge et al. 2000).

Nematode counts were transformed in logs $(x+1)$ for statistical analysis (Gomez \& Gomez 1984). Microsoft Excel was used to conduct the analysies.

\section{Results}

The survey data indicated that majority of the farmers (53\%) grew rice seedlings in fallow land and $20 \%$ of them grew after maize harvest. Others grew after linseed, sesame, kidney bean, cucumber, potato, tomato and onion (3.33\% each). 'Mansuli' was the dominant variety of rice $(36.6 \%)$ cultivated in the survey sites which was followed by 'Sabitri' (23.3\%). Other varieties were Barkhe 2001, Butche, Jhapali, Radha 4, Basmati, Loknath, OR 
and Sona Mansuli. None of the farmers used chemicals for seed and soil treatment, except one farmer, who treated seeds with Thiodan (an insecticide). Both shoot and root lengths were significantly higher in non-galled seedlings than galled seedlings (Figure 1). Galling of seedlings varied from 0 to $86 \%$ in different nurseries. Root-knot severity index and root lesion severity index were up to $19.9 \%$ and $55 \%$ respectively. Number of second stage juveniles (J2) recovered from $2 \mathrm{~g}$ root and $100 \mathrm{~g}$ soil were up to 33 and 37 respectively.



Fig. 1. Comparison of seedling and root length between galled and non-galled seedlings

Table 1. Comparison of population of M. graminicola (J2) and development of rice root-knot disease between upland and lowland

\begin{tabular}{l|l|l|l}
\hline S.N. & Parameters & Upland & Lowland \\
\hline 1 & J2 in Root & 12.26 & 0 \\
2 & J2 in soil & 13.39 & 0 \\
3 & Root galling percentage & 26.03 & 0 \\
4 & Root knot severity index & 4.66 & 0 \\
5 & Root lesion severity index & 31.12 & 47.50 \\
\hline
\end{tabular}

Table 2. Comparison of population of $M$. graminicola (J2) and development of rice root-knot disease between dry and wet seedbed

\begin{tabular}{l|l|l|l}
\hline S.N. & Parameters & Dry bed & Wet bed \\
\hline 1 & J2 in Root & 15.78 & 1.04 \\
2 & J2 in soil & 16.32 & 3.65 \\
3 & Root Galling Percentage & 33.73 & 1.63 \\
4 & Root knot severity index & 6.06 & 0.24 \\
5 & Root lesion severity index & 27.39 & 43.44 \\
\hline
\end{tabular}

Twenty nine farmers $(96.67 \%)$ grew seedlings in upland condition and only one in lowland. Under upland seedbed, approximately $26 \%$ seedlings were galled with the root-knot severity index of $4.66 \%$ and average number of $M$. graminicola $\mathrm{J} 2$ extracted form $2 \mathrm{~g}$ root and $100 \mathrm{~g}$ soil were 12 and 13 respectively (Table 1). However, there were no root-knots, J2 in soil and root under lowland seedbed but root lesion severity index was higher $(47.5 \%)$ than under upland seedbed (31.12\%). Approximately $73 \%$ farmers grew seedlings in dry bed and rest in wet bed. Percentage of galled seedling, root-knot severity index and number of $\mathrm{J} 2$ recovered from $2 \mathrm{~g}$ root and $100 \mathrm{~g}$ soil were significantly lower in wet bed than dry bed (Table 2). However, root lesion severity index was higher in wet bed (43.44\%) than in dry bed (27.39\%).

\section{Discussion}

Seedlings infected with $M$. graminicola grew slowly (Bridge \& Page 1982) because of root damage. As a result, galled seedlings had lower plant height and shorter roots. Since wet bed was kept in saturated condition by frequent irrigation, rice roots might escape invasion by M. graminicola (Bridge \& Page 1982) and/ or limited the spread of the nematode (Prot \& Matias 1995). Due to lower infection under wet bed condition, plant height, root length and root weight were increased but root-knot index and $\mathrm{J} 2$ number in root and soil were lower as compared to dry bed condition which was favorable for infection and development of $M$. graminicola. Similarly, under upland condition $M$. graminicola was able to infest most of the roots and resulted in drastic reduction in root development and consequential reductions in shoot growth (Prot \& Matias 1995). More damage from M. graminicola occurred in the aerobic upland systems (Soriano \& Reversat 2003). However, under lowland (continuous flooding), rice roots might escape invasion by $M$. graminicola (Bridge \& Page 1982) and limited the spread of the nematode (Prot \& Matias 1995). Permanent flooding might limit the migration of $\mathrm{J} 2$ between roots of the same system (Bridge \& Page 1982) resulting in a lower root damage. Reduced aeration due to high moisture levels for prolonged periods allowed poor respiration and movement of nematodes and reduced the population of M. graminicola (Garg et al. 1995). In addition to direct effects on the nematode, continuous flooding in lowland might increase tolerance of the rice seedlings towards M. graminicola (Soriano et al. 2000). Because of the lower infection and better plant health, 
plant height and root length were increased but rootknot index, root lesion index and $\mathrm{J} 2$ number in root and soil were decreased significantly in seedbed under lowland than under upland. Higher root lesion severity index observed in both lowland and wet bed may be due to the presence of other nematodes including Hirchmanniella sp.

Most of the farmers did not know about the nematode problem and did not follow any management practices to control it in nurseries and/or in the main field. So, there is high risk of multiplication of the nematodes which may cause huge loss in rice production. Thus, it is essential to manage $M$. graminicola from rice nurseries in order to produce healthy seedlings.

\section{Acknowledgement}

The financial assistance provided by Soil Management and Collaborative Research Support Program (SMCRSP) Cornell University, USA, is highly acknowledged. The authors are also thankful to the following SM-CRSP team members: Prof. Dr. John M. Duxbury and Dr. Julie G. Lauren for their valuable suggestions and continuous support to accomplish the study.

\section{References}

Bridge, J. and S.L.J. Page. 1982. The rice root-knot nematode, Meloidogyne graminicola, on deep-water rice (Oryza sativa subsp. indica). Revue de Nematologie 5(2):225-232.

Bridge, J., L. Michel and R.A. Plowright. 1990. Nematodes parasites of rice. In: Plant parasitic nematodes in subtropical and tropical agriculture (Eds. M. Luc, R.A. Sikora and J. Bridge). CAB International, Wallingford, UK. pp. 69-108.

Bridge, J., R.A. Plowright and D. Peng. 2005. Nematode parasites of rice. In: Plant parasitic nematodes in subtropical and tropical agriculture. $2^{\text {nd }}$ ed. (Eds. M. Luc, R.A. Sikora and J. Bridge). CABI Publishing, CAB International, Wallingford, UK. pp. 87-130.

Dahal, G.P., P. Amatya and H.K. Manandhar. 1992. Bibliographic database on plant pathology in Nepal. Journal of Institute of Agriculature and Animal Science 13:53-64.

Dangal, N.K., D. Sharma-Poudyal, S.M. Shrestha, C. Adhikari, J.M. Duxbury and J.G. Lauren. 2008. Evaluation of organic amendments against rice rootknot nematode at seedling stage of rice. Nepal Journal of Science and Technology 9: 21-27.

Dhital, B.K., T.B. Gurung, R.P. Bari and K.D. Subedi. 1995. Agronomic research on rice. LARC working paper, Lumle, Kaski. No. 96:51.
Garg, R.N., H.S. Gaur and G. Singh. 1995. Effect of puddling and water regimes on soil physical properties, plant parasitic nematodes and performance of rice crop. Annals of Plant Protection Sciences 3(2):121-126.

Gomez, K.A. and A.A. Gomez. 1984. Statistical procedures for agricultural research. $2^{\text {nd }} \mathrm{ed}$. Johns and Sons. New York. $591 \mathrm{pp}$

Kataki, P. 2001. Rice and wheat production trend, constrraint, and opportunities in Nepal. In: Rice-wheat based cropping systems in South Asia, trends, constraint, productivity and policy (Ed. P. Kataki). Haworth Press, New York. pp. 1-35.

Kataki, P.K., P. Hobbs and B. Adhikary. 2001. The ricewheat cropping system of South Asia: trends, constraints and productivity- A prologue. In: The ricewheat cropping system of South Asia: trends, constraints, productivity and policy (Ed. P. K. Kataki). Food products press, an imprint of The Haworth Press, Inc., New York. pp. 1-26.

NARC. 2001. NARC annual report 1999/2000. Communication, Publication and Documentation Division, Nepal Agriculture Research Council, Khumaltar.

Panwar, M.S. and Y.S. Rao. 1998. Status of phytonematodes as pests of rice. In: Nematode disease in plant (Ed. P.C. Trivedi). CBS Publishers and Distributors, New Delhi, India. pp. 49-81.

Pokharel, R.R. 2007.Characterization of root-knot populations from rice-wheat fields in Nepal and reactions of selected rice and wheat germplasm to Meloidogyne graminicola- Ph.D. dissertation. Cornell University, Ithaca, New York, USA.

Pokharel, R.R. and D. Sharma-Poudyal. 2001. Potentially economically important nematodes in rice-wheat systems and the importance of $M$. graminicola in rice. Final report submitted to Rice-Wheat Project of IRRI/ CIMMYT/NARC.

Pokhrel, R.R. 2001. Rice cropping patterns and plant parasitic nematodes. Journal of Institute of Agriculture and Animal Science 21-22:187-196.

Prot, J.C. 1994. The combination of nematodes, Sesbania rostrata, and rice: the two sides of the coin. International Rice Research Newsletter 19:30-31.

Prot, J.C. and D.M. Matias. 1995. Effects of water regime on the distribution of Meloidogyne graminicola and other root parasitic nematode in a rice field toposequence and pathogenicity of $M$. graminicola on rice cultivar UPLR 15. Nematologica 41:219-228.

Schindler, A.F. 1961. A simple substitue for a Baermann funnel. Plant Disease Reporter 45:747-748.

Sharma, D., J. Bridge, S.M. Shrestha, E. Duveiller, M. Rutherford, S. Sharma, D.B. Gharti and G. Sah. 2002. 
Nematode assessment in minimum and conventionally tilled rice-wheat fields in Nepal. In: Soil health and sustainability of the rice-wheat systems of the Indo-Gangetic Plains (Eds. E. Duveiller, J. Bridge, M. Rutherford and S. Keeling). Proceedings of the end of project workshop, 7-10 May 2002, Kathmandu, Nepal. pp. 37-44.

Sharma, S.B. and P.F. Rahaman. 1998. Nematode pests in rice and wheat cropping systems in the IndoGangatic plain. In: Nematode pets in rice-wheatlegume cropping systems (Eds. S.B. Sharma, C. Johasan, and S.E. Midha). Proceedings of a regional training course 1-5 September 1997, CCS Harayana Agricultural University, Hisar, Harayana, India. Rice-Wheat Consortium paper series 4. New Delhi, India: Rice-Wheat Consortium for the IndoGangatc Plains. pp. 11-16.

Sharma, S.B., S. Pande, M. Saha, K.K. Kaushal, M. Lal, M. Singh, K. Singh, R. Pokharel, R.P. Upreti and K. Singh. 2001. Plant parasitic nematodes associated with rice and wheat based cropping systems in
Nepal. International Journal of Nematology 11:35-38.

Sharma-Poudyal, D., R.R. Pokharel, S.M. Shrestha and G.B. Khatri-Chhetri. 2002. Population and effect of rice root-knot nematode in diseased and healthy looking rice plants and their distribution in rice field. Journal of Institute of Agriculture and Animal Science 23:9-14.

Sharma-Poudyal, D., R.R. Pokharel, S.M. Shrestha and G.B. Khatri-Chhetri. 2004. Evaluation of common Nepalese rice cultivars against rice root-knot nematode. Nepal Agriculture Research Journal 5:33-37.

Soriano, I.R. and G. Reversat. 2003. Management of Meloidogyne graminicola and yield of upland rice in South-Luzon, Philippines. Nematology 5(6):879-884.

Soriano, I.R.S., J.C. Prot and D.M. Matias. 2000. Expression of tolerance for Meloidogye graminicola in rice cultivars as affected by soil type and flooding. Journal of Nematology 32(3):309-317. 
Nepal Journal of Science and Technology 10 (2009) 